УДК 373.1

DOI 10.23951/2307-6127-2020-1-21-26

\title{
РАЗВИТИЕ ИНФОРМАЦИОННОЙ ГРАМОТНОСТИ УЧАЩИХСЯ В УСЛОВИЯХ СЕЛЬСКОЙ ШКОЛЫ
}

\author{
М. В. Александрова, А. Г. Ширин, С. М. Тайков
}

Новгородский государственный университет имени Ярослава Мудрого, Великий Новгород

\begin{abstract}
Описаны вопросы разновозрастного обучения в сельской школе. Представлены основные компоненты информационной грамотности учащихся школы (получение информации; оценка информации; использование информации). Раскрыто понятие «информация». Изучена связь информационной грамотности с такими видами грамотности, как сетевая грамотность (умение анализировать данные, поступающие из социальных сетей); цифровая грамотность (умение воспринимать и применять информацию с помощью компьютера); интернет-грамотность (умение критически оценивать информацию из сети Интернет); компьютерная грамотность (способность грамотно применять информационно-коммуникационные технологии для решения поставленных задач); медиаграмотность (способности, необходимые для взаимодействия с данными, информацией и знаниями).
\end{abstract}

Ключевые слова: информационная грамотность, учащиеся сельской школьы.

Современное обилие вычислительных технологий и их повсеместное распространение во всех сферах жизни диктует необходимость уверенно ориентироваться в этом многообразии, правильно подбирать IT-инструменты для решения тех или иных задач, уметь защищать и сохранять ценную информацию. Задачей образования становится не просто передача знаний и подготовка подрастающего поколения к будущей профессиональной деятельности, а развитие личности, способной своевременно находить, воспринимать, анализировать, продуктивно использовать полученную информацию.

Необходимость освоения школьниками основ информационной грамотности, выступающих в качестве обязательных требований к овладению компетентностями, позволяющих удовлетворить собственные образовательные интересы и потребности, находит отражение в Законе об образовании в РФ и федеральном государственном образовательном стандарте основного общего образования, федеральной целевой программе «Электронная Россия».

Анализ научной литературы показал многоплановость и сложность рассматриваемой проблемы. Вопросы информатизации образования, подготовки старшеклассников с углубленным изучением информатики рассматриваются в научной литературе по следующим направлениям: психолого-педагогические особенности применения компьютерных технологий в образовании (А. Г. Гейн, А. П. Ершов, М. П. Лапчик, В. М. Монахов и др.); использование информационно-коммуникационных технологий (ИКТ) в сельской малокомплектной школе (Э. А. Ахметова, С. М. Авдеева и др.); применение компьютерных технологий в совершенствовании образовательного процесса (Я. А. Ваграменко, Б. С. Гершунский, Е. И. Машбиц, Е. С. Полат, И. В. Роберт и др.); формирование профессиональных качеств будущих специалистов (Е. В. Бондаревская, А. М. Новиков, В. В. Сериков, К. Д. Чермит, В. Д. Шадриков и др.); формирование информационной культуры (А. А. Гречихин, Н. Б. Зиновьева, Н. М. Розенберг, И. Е. Ширшов и др.); особенности применения информационных технологий в классах с гуманитарным профилем обучения (М. П. Лапчик, Ю. С. Барановский, И. Б. Готская и др.). 
В соответствии с Указом Президента РФ «О национальных целях и стратегических задачах развития Российской Федерации на период до 2024 г.» воспитание гармоничной и всесторонне развитой личности является приоритетным в сфере образования. В связи с наметившейся тенденцией развития информационно грамотного общества повышается потребность в создании информационно развивающей среды сельской школы с целью использования потенциальных возможностей сети Интернет. Так, информационная грамотность находится в перечне компетенций, развитие которых определено актуальными школьными стандартами. Согласно ФГОС ООО, школа, в том числе и сельская, должна обеспечить образование и формирование личности школьника, соответствующие общемировым тенденциям развития глобального информационного общества и обеспечить конкурентоспособность России в мире за счет создания необходимых предпосылок для инновационного развития.

Однако в 2013 г. в ходе международного исследования грамотности школьников ICILS, проверяющего компетенции в сфере ИКТ, выяснилось, что выпускники российских школ демонстрируют низкое владение информационной грамотностью. Продвинутых пользователей компьютера в российских школах лишь 2 \%. Это означает, что обучение с использованием онлайн-инструментов, например портала Coursera, не для России, так как от каждого слушателя ожидаются самостоятельность и умение работать за компьютером. В связи с этим возникает объективная потребность в развитии информационной грамотности школьников в условиях общеобразовательной школы.

Современное обилие вычислительных технологий и их повсеместное распространение во всех сферах жизни диктуют необходимость уверенно ориентироваться в этом многообразии, правильно подбирать IT-инструменты для решения тех или иных задач, уметь защищать и сохранять ценную информацию.

На современном этапе развития общества наблюдается процесс стремительного насыщения общества техническими средствами массовой коммуникации, в связи с чем при характеристике нашего времени мы можем встречать такие понятия, как «век информации», «информационная цивилизация». Сам термин «информационное общество» ввели в обращение еще в 60-70-х гг. ХХ в. (Д. Белл, Е. Масуда, А. Тоффлер) [1].

Современный школьник нуждается в получении информации не меньше, чем взрослые люди. Дети регулярно сталкиваются с большим количеством информации, поступающей извне, и, для того чтобы не потеряться в огромном информационном пространстве, им необходимо иметь навыки работы с ней, основы которых закладываются в школе. В процессе формирования у школьников информационной грамотности важное место занимают уроки информатики, а значимым результатом становится умение работать с информацией, умение использовать способы ее накопления, обработки и передачи, а не только умение пользоваться компьютерами и программами. Поэтому школа, находящаяся даже в самой глубинке, не может обходиться без компьютеров.

Сегодня значение информации, а также средств ее обработки и передачи возрастает. Мы можем говорить о том, что IT-технологии определяют научно-технический потенциал страны, уровень ее развития и образ жизни человека. Приобретение и использование информации является необходимым условием эффективного функционирования общества.

Термин «информация» является многофункциональным и используется в различных областях научной и общественной жизни. Именно данное понятие является основой курса информатики. Так, информация становится важным компонентом образования и научнотехнического прогресса. Перед разными слоями населения (учащимися школы, работающим 
населеним и т. д.) появляющаяся и постоянно усложняющаяся информация ставит много проблем.

В наиболее широком понимании грамотность трактуется как «состояние образованности». Грамотность формируется на этапе начального и среднего образования, как правило в государственных школах, но также основами грамотности можно овладеть и в семье.

Грамотность становится приоритетом современного пользователя Интернета. Интернет является частью образования, а также местом для развлечений и проведения досуга учащимися. Так, информационная грамотность входит в перечень компетенций, формирование которых предполагает современный школьный стандарт.

Вместе с тем необходимо понимать, что информационная грамотность формируется в процессе всего обучения, а не только на уроках информатики.

Первое упоминание термина «информационная грамотность» зафиксировано в 1977 г. в США, оно использовалось в документе национальной программы реформы высшего образования. Американская библиотечная ассоциация называет информационно грамотным человеком такую личность, которая способна выявлять, размещать и оценивать информацию и наиболее эффективно ее использовать [1].

Таким образом, информационная грамотность включает в себя такие этапы, как осознание потребности в информации, ее нахождение и получение, оценка и анализ полученной информации и использование информации для решения задачи.

Согласно И. А. Смольниковой, быть информационно грамотной личностью - это значит обладать способностью понимать востребованность информации, умением ее находить, оценивать и эффективно использовать.

Отечественные и зарубежные ученые отмечают, что информационная грамотность связана с такими видами, как сетевая грамотность (способность к сбору и анализу информации в социальных сетях); цифровая грамотность (умение воспринимать и применять информацию с помощью компьютера - П. Гилстер, А. В. Шариков и др.); интернет-грамотность (И. И. Трубина, А. Таранцов и др.), компьютерная грамотность (способность грамотно применять ИКТ для решения поставленных задач - Б. С. Гершунский, Ф. Хортон и др.); медиаграмотность (способности, необходимые для взаимодействия с данными, информацией и знаниями, - А. С. Резцов, А. Ю. Уваров и др.) [2].

Сегодня в научных исследованиях, посвященных проблемам образования, отмечается, что информационная грамотность школьников является начальным уровнем для формирования их информационной компетентности [3].

Важной составляющей в процессе формирования информационной грамотности является еще и тот факт, что в современном обществе наблюдается появление новых профессий, ранее не существовавших.

Ученые и педагоги подчеркивают, что на современном этапе развития общества возросла информированность детей. Ранее школа выступала основным источником получения ребенком информации о мире, человеке, обществе, природе, сегодня значительная часть информации поступает из средств массовой информации и оказывает существенное влияние на становление картины мира подрастающего поколения. Современные педагоги считают, что система образования должна в полной мере использовать новые информационные технологии начиная с младших классов.

Разберем конкретный пример сельской школы, где обучается порядка 70 детей. Даже в такой маленькой школе для учебного процесса требуются компьютеры, в указанной школе их шесть. Также имеется несколько принтеров, сканер и одно проекционное устройство. Этого достаточно, чтобы интегрировать современные информационные технологии в 
учебный процесс и позволить персоналу школы пользоваться необходимым программным обеспечением (составление поурочного планирования, создание презентации к уроку, мониторинг развития учеников, взаимодействие с другими школами) [4].

Вместе с тем следует учитывать, что в сельской школе наверняка используется компьютерная техника 5-10-летней давности, отсутствует финансирование на модернизацию и обучение кадров. Порог вхождения для использования современных технологий (база необходимых знаний и компетенций) постоянно повышается, что усугубляется все возрастающими требованиями к материально-техническому обеспечению. Сочетание этих факторов ограничивает возможности ученика сельской школы в плане реализации своего потенциала и получения качественного образования. После введения ЕГЭ и ОГЭ ситуация ухудшилась, обострив противоречия между необходимостью выполнения ФЗ «Об образовании в РФ» для школ с малым количеством учеников и устаревшей материальной базой, и вопрос экономической целесообразности существования малокомплектных школ стал еще более актуальным. Для решения таких проблем требуются разносторонний анализ и проработка нескольких возможных направлений развития информатизации школы, позволяющих поэтапно повысить информационную грамотность как учеников, так и сотрудников школы. При этом необходимость использования ИКТ в воспитательном процессе обусловлена несколькими факторами - возрастает поток информации, механическая обработка данных становится все более трудозатратной, а постоянно меняющаяся среда требует оперативного анализа для принятия управленческих решений $[5,6]$.

При разработке проекта информатизации сельской школы необходимо учитывать тот факт, что группы обучающихся в малокомплектных школах часто являются разновозрастными, причем дети могут не только отличаться по возрасту, но и обучаться по разным учебным программам. Это повышает требования к мастерству педагога, который организует и проводит такое занятие, ведь ему необходимо обеспечить взаимодействие учеников из разных классов [7].

Учитель, который планирует работать в сельской школе, должен иметь специфические знания, которые потребуются ему для организации эффективного процесса обучения. Ему потребуется изучить аспекты организации межвозрастного обучения, учесть фактор объединения учеников из разных классов и научиться организовывать уроки для изучения отдельных тем в разновозрастных группах [8].

При этом необходимо создавать условия, в которых возможно формирование профессиональной компетентности педагогов, что позволит решить задачу модернизации образования в сельских учебных учреждениях. Сюда относятся разработка и реализация проектов развития учебного учреждения, программ профессионального роста педагогов, обновления материально-технической базы. После реализации проектов слушатели (учебный и административный персонал) должны овладеть определенными компетенциями, в числе которых умение выделять особенности формирования содержания образования, умение применять межпредметные связи для активизации познавательной деятельности учащихся, умение проектировать модели формирования разновозрастного содержания $[9,10]$.

Итак, формирование информационной грамотности учащихся сельской школы является составляющей информационной культуры личности в целом, а приобретаемые информационные компетенции становятся ключевым фактором в образовании подрастающего поколения. Овладение информационными компетенциями становится основой для достижения образовательных целей, поэтому их необходимо развивать в течение всей жизни, а особенно в годы учебы в школе. 


\section{Список литературы}

1. Аксёнова Э. А. Развитие информационной грамотности российских школьников // Школьные технологии: науч.-практ. журн. 2015. № 5. С. 3-15.

2. Суви Туоминен, Сиркку Котилайнен. Педагогические аспекты формирования медийной и информационной грамотности. М.: Институт ЮНЕСКО по информационным технологиям в образовании, 2012. 142 с.

3. Лау X. Руководства по информационной грамотности на протяжении всей жизни / русский пер. Guidelines on Information Literacy for Lifelong Learning. Последняя редакция: 30 июля 2006 г. 45 с.

4. Ахметова Э. А. Использование информационно-коммуникационных технологий в сельской малокомплектной школе // Вестн. Марийского гос. ун-та. 2010. С. 41-44.

5. Эскаева Т. А. Внедрение ИКТ в практику управления образованием в сельской школе // Вестн. Марийского гос. ун-та. 2009. C. 40-45.

6. Колченко Л. В. Особенности внедрения информационно-коммуникационных технологий в учебно-воспитательный процесс школы // Мир науки, культуры, образования. 2009. № 4 (16). С. 109-111.

7. Дощанова Б. М. Разновозрастное обучение в малокомплектной школе // Современная высшая школа: инновационный аспект. 2012. № 1. С. 93-94.

8. Байгулова Н. В., Сартакова Е Е. Педагогические условия профессиональной подготовки учителя для сельских малокомплектных образовательных учреждений // Вестн. Томского гос. пед. ун-та (TSPU Bulletin). 2009. Вып. 1 (79). C. $32-36$.

9. Михайличенко А. Ю., Никульшин С. М. К вопросу о формировании профессиональной компетентности педагогов сельских малокомплектных школ // Вестн. Томского гос. пед. ун-та (TSPU Bulletin). 2010. Вып. 11 (101). С. $86-89$.

10. Байгулова Н. В. Педагогические условия эффективного функционирования сельских малокомплектных школ // Вестн. Томского гос. пед. ун-та (TSPU Bulletin). 2016. Вып. 1 (166). С. 138-143.

Александрова Марина Викторовна, доктор педагогических наук, профессор, Новгородский государственный университет имени Ярослава Мудрого (ул. Большая Санкт-Петербургская, 41, Великий Новгород, Россия, 173003). E-mail: Marina.Aleksandrova@novsu.ru

Ширин Александр Глебович, доктор педагогических наук, доцент, Новгородский государственный университет имени Ярослава Мудрого (ул. Большая Санкт-Петербургская, 41, Великий Новгород, Россия, 173003). E-mail: Alexander.Shirin@novsu.ru

Тайков Сергей Михайлович, магистрант, Новгородский государственный университет имени Ярослава Мудрого (ул. Большая Санкт-Петербургская, 41, Великий Новгород, Россия, 173003). E-mail: aeorn@mail.ru

Материал поступил в редакциию 04.12.2019.

DOI 10.23951/2307-6127-2020-1-21-26

\section{DEVELOPMENT OF STUDENTS INFORMATION LITERACY IN A RURAL SCHOOL}

\section{V. Aleksandrova, A. G. Shirin, S. M. Taykov}

Yaroslav-the-Wise Novgorod State University, Veliky Novgorod, Russian Federation

We described the issues of different age education in a rural school and presented the main components of information literacy of school students (obtaining information; evaluating information; using information). The concept of "information" is disclosed. We studied the relationship of information literacy with such types as network literacy (the ability to analyze, collect and use information coming from social networks); digital literacy (the ability to understand and use information provided by a variety of formats and sources using a computer); internet literacy; computer literacy (knowledge, skills and abilities necessary for understanding information and communication technologies, including hardware, software, systems, networks (local networks and the Internet)); media literacy (knowledge, skills and abilities necessary for understanding all means of (mass) communication and formats in 
which the creation, storage, transmission and presentation of data, information and knowledge is carried out). We gave examples and analysis of the current situation in rural schools, the reasons why it is necessary to develop and implement information and communication technologies in small schools and the practice of their application. We also described the main directions of development of teachers in rural schools (areas that require special attention when designing a development program for a particular school) and the conditions that are necessary for this.

Keywords: information literacy, rural school students.

\section{References}

1. Aksyonova E. A. Razvitiye informatsionnoy gramotnosti rossiyskikh shkol'nikov [The development of information literacy of Russian schoolchildren]. Shkol'nyye tekhnologii: nauchno-prakticheskiy zhurnal - Journal of School Technology, 2015, no. 5, pp. 3-15 (in Russian).

2. Tuominen S., Kotilainen S. Pedagogicheskiye aspekty formirovaniya mediynoy i informatsionnoy gramotnosti [Pedagogical aspects of the formation of media and information literacy]. UNESCO Institute for Information Technologies in Education Publ., 2012, pp. 142 (in Russian).

3. Lau H. Rukovodstva po informatsionnoy gramotnosti na protyazhenii vsey zhizni [Guidelines for Lifelong Information Literacy]. Russian translation of Guidelines on Information Literacy for Lifelong Learning. Latest edition: July 30, 200, pp. 45 (in Russian).

4. Akhmetova E. A. Ispol'zovaniye informatsionno-kommunikatsionnykh tekhnologiy v sel'skoy malokomplektnoy shkole [The use of information and communication technologies in a rural low-grade school]. Vestnik Mariyskogo gosudarstvennogo universiteta - Vestnik of the Mari State University, 2010, no. 5, pp. 41-44 (in Russian).

5. Eskayeva T. A. Vnedreniye IKT v praktiku upravleniya obrazovaniyem v sel'skoy shkole [The introduction of ICT in the practice of education management in a rural school]. Vestnik Mariyskogo gosudarstvennogo universiteta - Vestnik of the Mari State University, 2009, no. 3, pp. 40-45 (in Russian).

6. Kolchenko L. V. Osobennosti vnedreniya informatsionno-kommunikatsionnykh tekhnologiy v uchebno-vospitatel'nyy protsess shkoly [Features of the implementation of information and communication technologies in the educational process of the school]. Mir nauki, kul'tury, obrazovaniya, no. 4 (16), 2009, pp. 109-111 (in Russian).

7. Doshchanova B. M. Raznovozrastnoye obucheniye v malokomplektnoy shkole [Different-age education in a low-grade school]. Sovremennaya vysshaya shkola: innovatsionnyy aspekt - Contemporary Higher Education: Innovative Aspects, 2012, no. 1, pp. 93-94 (in Russian).

8. Baygulova N. V., Sartakova E. E. Pedagogicheskiye usloviya professional'noy podgotovki uchitelya dlya sel'skikh malokomplektnykh obrazovatel'nykh uchrezhdeniy [Pedagogical conditions of teacher training for rural ungraded educational institutions]. Vestnik Tomskogo gosudarstvennogo pedagogicheskogo universiteta - TSPU Bulletin, 2009, vol. 1 (79), pp. 32-36 (in Russian).

9. Mikhaylichenko A. Yu., Nikul'shin S. M. K voprosu o formirovanii professional'noy kompetentnosti pedagogov sel'skikh malokomplektny 'kh shkol [On the question of the formation of professional competence of teachers of rural low-grade schools]. Vestnik Tomskogo gosudarstvennogo pedagogicheskogo universiteta - TSPU Bulletin, 2010, vol. 11 (101), pp. 86-89 (in Russian).

10. Baygulova N. V. Pedagogicheskiye usloviya effektivnogo funktsionirovaniya sel'skikh malokomplektny'kh shkol [Pedagogical conditions for the effective functioning of rural ungraded schools]. Vestnik Tomskogo gosudarstvennogo pedagogicheskogo universiteta - TSPU Bulletin, 2016, vol. 1 (166), pp. 138-143 (in Russian).

Aleksandrova M. V., Yaroslav-the-Wise Novgorod State University (ul. Bol'shaya SanktPeterburgskaya, 41, Velikiy Novgorod, Russian Federation, 173003). E-mail: Marina.

Aleksandrova@novsu.ru

Shirin A. G., Yaroslav-the-Wise Novgorod State University (ul. Bol'shaya Sankt-Peterburgskaya, 41, Velikiy Novgorod, Russian Federation, 173003).E-mail: Alexander.Shirin@novsu.ru

Taykov S. M., Yaroslav-the-Wise Novgorod State University (ul. Bol'shaya Sankt-Peterburgskaya, 41, Velikiy Novgorod, Russian Federation, 173003). E-mail: aeorn@mail.ru 